\title{
The labor share and income inequality: some empirical evidence for the period 1990-2015
}

\author{
Iñaki Erauskin \\ Deusto Business School, University of Deusto, \\ $P^{o}$ Mundaiz Donostia-San Sebastián, Spain

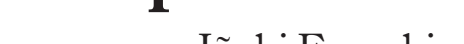

Labor share and income inequality

Received 14 April 2020 Revised 27 June 2020 27 July 2020 Accepted 27 July 2020

\begin{abstract}
Purpose - The purpose of this paper is to analyze empirically the relationship between the labor share and income inequality, as measured by the Gini coefficient and by the income shares for different quintiles, during the period 1990-2015 for 62 developed and developing countries.
\end{abstract}

Design/methodology/approach - This study uses panel data techniques to analyze empirically the relationship between the labor share and income inequality.

Findings - This paper finds that a lower labor share is associated with a higher Gini coefficient. A lower labor share is found to be strongly associated with a smaller income share for the lowest two quintiles and larger income share for the highest quintile and weakly associated with a smaller income share for the third and fourth quintiles. Moreover, this paper finds that the lower the quintile, the stronger the impact of the labor share on the income share of the quintile.

Social implications - Policymakers should take into account the evolution of the labor share. Public policies that improve labor market outcomes, such as those aimed to promote participation in the labor market and strengthen the human capital of low-income groups, seem necessary to prevent the rise in economic inequalities. Moreover, as the digital transformation of society progresses, policies to promote skill deepening may have an important role in reversing excessive inequalities.

Originality/value - How changes in the labor share are associated with changes in the Gini coefficient, and how this is driven by income shares for different quintiles, for a broad range of countries during the most recent period, has not been comprehensively studied using panel data techniques.

Keywords Labor share, Inequality, Gini coefficient, Income share, Quintile

Paper type Research paper

\section{Introduction}

The labor share, that is, the share of national income received by workers, has been documented to be declining in most developed and developing countries since the 1980s and especially since the early 1990s [1]. For instance, the share of labor was slightly above 55\% in 1990, while it was around 50\% in 2015 [2]. At the same time, empirical evidence shows that during recent years income inequality has increased in many countries [3]. For example, in the USA the Gini coefficient has increased from 0.394 in 1970, to 0.428 in 1990 and further to 0.479 in 2015. In China, the Gini coefficient was 0.291 in 1981, 0.327 in 1990 and increased rapidly to 0.462 in 2015 [4]. Both facts seem to suggest that increasing income inequality

(C) Iñaki Erauskin. Published in Applied Economic Analysis. Published by Emerald Publishing Limited. This article is published under the Creative Commons Attribution (CC BY 4.0) licence. Anyone may reproduce, distribute, translate and create derivative works of this article (for both commercial and non-commercial purposes), subject to full attribution to the original publication and authors. The full terms of this licence may be seen at http://creativecommons.org/licences/by/4.0/legalcode

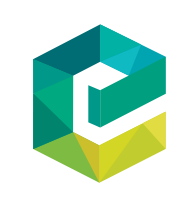

Applied Economic Analysis Vol. 28 No. 84,2020 pp. $173-195$ 
AEA 28,84 may be associated with the decline of the labor share. However, this relationship has been sparsely studied so far.

The relationship between declining labor share and increasing income inequality may seem obvious at first sight: to the extent that labor (capital) share is more evenly (unevenly) distributed, declining (increasing) labor (capital) share is likely to be associated with higher income inequality. However, the relationship between the labor share and income inequality depends not only on the distribution of labor and capital incomes but also on other factors, such as the impact of social transfers and taxes, for instance, which may work in the opposite direction. In fact, inequality increased (diminished) when labor share increased (diminished) in some countries, such as China, Canada, Mexico and some others. More generally, this has occurred in 22 countries (out of 62 countries) while the opposite has occurred in 40 countries between 1990 and 2015. Therefore, the relationship between the labor share and income inequality is not as straightforward as it apparently seems.

There are only a few studies relating to the labor share and income inequality, as we detail in Section 2. However, how changes in the labor share are associated with changes in income inequality, as measured by the Gini coefficient and how this is driven by income shares for different quintiles, for a broad range of countries during the most recent period, has not been comprehensively studied using panel data techniques, as far as we know.

The objective of this paper is to provide a more comprehensive empirical investigation into how higher income inequality has been associated with the declining share of labor that has occurred over the period 1990-2015, in contrast to earlier contributions to the literature. We do so by focusing on several aspects not addressed before, such as analyzing empirically the relationship between the declining labor share and income inequality, as measured by the Gini coefficient. This is followed by a study of how this relationship is driven by income shares for quintiles, for 62 countries during the most recent period 1990-2015, using panel data techniques. We find that a lower labor share is associated with a higher Gini coefficient. Why is this so? A lower labor share is found to be strongly associated with a smaller income share for the lowest two quintiles and larger income share for the highest quintile and weakly associated with a smaller income share for the third and fourth quintiles. Moreover, we find that the lower the quintile, the stronger the relationship between the labor share and the income share of the quintile [5].

We should note that our paper is focused on the relationship on income inequality which is more "broadly" defined, based on the usual Gini coefficient and income shares by quintiles, rather than the more "narrowly" defined top income inequality [6]. This is a reasonable choice, given that the purpose of this paper is to analyze the relationship between the labor share and income inequality, which presumably would affect the complete distribution of income and not just the distribution of top income. Alvaredo (2011) shows under which conditions, and how, both measures of inequality, Gini coefficient and top 1\% inequality, are related.

The remainder of the paper proceeds as follows. Our motivation for this topic and a brief literature review are provided in Section 2. Data sources are described in Section 3. The econometric empirical evidence is provided in Section 4, while Section 5 presents our conclusions. A simple numerical example based on a stylized model on the relationship between the labor share and income inequality is provided in Section A, which has been relegated to the Appendix for convenience. 


\section{Motivation and related literature}

Table 1 summarizes some key statistics on the labor share and income inequality, as measured by the Gini index, both ranging from 0 to 100, from 1990 to 2015 every five years, which serve to motivate our analysis. We observe that the labor share declines from 1990 onward, quickly at first, then more slowly, with greater variability, especially as the Great Recession arrives. A similar, but opposite, the trend seems to be the case for the Gini index, which increases quickly at first, then more slowly, again with greater variability coinciding with the Great Recession. This relationship between the declining labor share and increasing income inequality can be conveniently captured using a simple example, derived from a stylized model built by García-Peñalosa and Turnovsky (2006) to analyze the relationship between economic growth and income inequality. The interested reader is referred to the Appendix for more details.

The reasons for the declining labor share is declining have received much attention during recent years and different explanations have been provided to explain it [7]. An increase in wage inequality in developed countries has been documented commencing in the 1980s, suggesting skill-biased technological change as its primary cause [8]. The fall in the relative price of investment goods, thus substituting labor for capital, may also have been an important factor behind the decline in the share of labor [9]. The increase in market power may also have had an important impact on the decline [10]. Other factors having an impact on the decline of the labor share include global integration (which refers to trade openness, global value chains and financial globalization), on the one hand, and policies, institutions and regulations, on the other hand [11].

The few studies analyzing the relationship between the labor share and income inequality differ in the countries and periods covered, as well as in the methodologies employed. Daudey and García-Peñalosa (2007) find that a larger labor share is associated with a lower Gini coefficient for 39 developed and developing countries between 1970 and 1994. Checchi and García-Peñalosa (2010) also find the same result for 16 OECD countries over the period 1960-2000. Wolff (2010) shows that capital ownership is mainly concentrated among the top of the income distribution, thus increasing (reducing) the capital (labor) share and income inequality for the USA during the period 2001-2007. Adler and Schmid (2013) find that declining labor income shares are associated with growing inequality in Germany during 2002-2008. Jacobson and Occhino (2012) suggest that the decline in the labor share is associated with increasing income inequality in the USA for the most recent period until 2010. Contrary to other findings, Francese and Mulas-Granados (2015) suggest that the labor share is not a determinant for inequality, but rather inequality of wages, based on a sample for 93 countries during the period 1970-2013. More recent research, such as Dao et al. (2017) and IMF (2017), suggests that lower labor share is associated with higher Gini coefficients for 49 countries (mostly advanced countries) between 1991 and 2014. Sauer et al. (2020) find that the most robust factor behind rising
Labor share and income inequality

\begin{tabular}{lccc}
\hline Year & Labor share & Average Gini & \\
\hline 1990 & 55.6 & 36.7 \\
1995 & 54.3 & 37.5 & \\
2000 & 53.5 & 38.4 & \\
2005 & 51.3 & 38.3 & Table 1. \\
2010 & 50.2 & 39.0 & Some basic statistics \\
2015 & 49.9 & 40.1 & \\
\hline
\end{tabular}


income inequality is declining labor share for 73 countries (mostly observations from 28,84 advanced OECD countries) between 1981 and 2010.

\section{Data sources}

There are many ways to measure economic inequality. The most widely used measure for economic inequality is the Gini coefficient. However, the Gini coefficient can be expressed in net or gross terms, it can be based on income or consumption data or it can be provided by individuals or households. There are also different sources of data providing the Gini coefficient, which suggests that the Gini coefficient is likely to be different from some data sets to others. In addition, Gini coefficients can also be based on actual household surveys or on estimates based on imputations (through regressions) or other methods. Thus, choosing between different data sets involves evaluating the accuracy, the comparability and the coverage of data, which are subject to trade-offs. Data sets based on actual data are typically preferred to data sets based on imputation methods because the former is usually more accurate and reliable [12]. However, this also usually implies smaller coverage. The best source for actual data on inequality is probably the "All the Ginis" (ATG henceforth) database, compiled by Branko Milanovic (since 2004) to "standardize" Gini coefficients, due to its coverage and comparability from different sources among countries [13]. The best source for imputation-based data sets is probably the Standardized World Income Inequality Database (SWIID henceforth), produced by Solt $(2009,2016)$ [14]. We choose the ATG database for being based on actual data [15] and, conveniently, it allows us to capture conveniently data set heterogeneity through dummies.

Data on the Gini coefficient is based on Branko Milanovic's "ATG" database, which is based, in turn, on data provided by independent sources (INDIE), Luxembourg Income Study (LIS), SocioEconomic Database for Latin America and the Caribbean (SEDLAC), European Union Statistics on Income and Living Conditions (EU-SILC), Eastern Europe and Central Asia from the World Bank (ECA), World Income Distribution (WYD), World Bank (POVCAL) and World Income Inequality Database (UNU-WIDER). The latest version of ATG (February 2019) has been subject to a significant change with respect to the earlier one (October 2016). In earlier versions a new variable called Giniall was created from those nine (now eight) sources, summarizing all the sources and providing only one value per country and year. Thus, when there was more than one observation per country and year coming from different sources, the choice was made following "the choice by precedence" using the best data as the first choice and then the second best, then the third best, and so on, "which in our [their] view reflects the reliability, degree of variable standardization and consistency of geographic coverage of each data set, to create a "standardized" Gini. This newly created variable is called Gimiall' (Milanovic, 2016b, p. 5). However, Giniall has been dropped from the latest version of ATG for lack of consistency [16].

Choosing the "best" data from the ATG database (the most recent one or earlier ones) involves trade-offs, concerning the accuracy and comparability of the data and the size of the sample, as is usual for any database. Given that our objective is to analyze the relationship between the labor share and inequality for the period 1990-2015, we want to maximize the size of the sample, subject to the data being accurate and comparable. We use first "the choice of precedence" suggested by Branko Milanovic in earlier versions to maximize sample size, being as accurate as possible and then we make further adjustments to make data as comparable as possible capturing source, methodology, country, a year or other type of heterogeneity through dummies. First, the choice by precedence of the sources used is as follows: INDIE, LIS, EDLAC, EU-SILC, ECA, WYD and POVCAL[17]. Second, we make further adjustments through dummies. We include one dummy variable per source (LIS, SEDLAC, SILC, ECA, WYD and POVCAL) to capture source heterogeneity. Furthermore, given that independent sources come 
from various data sets for different countries and they usually do not cover all the years of the sample, we have also included country dummies for these 17 countries for the years where independent sources have been employed. Moreover, ATG reports Gini coefficients based on the three alternate measures. First, the Gini coefficient can be an income- or consumption-based measure. Second, it can be based on data provided by individuals or households. Third, the Gini coefficient can be obtained from gross (before tax) or net (after-tax) income. Thus, we take as the benchmark case the most common concept of the Gini coefficient, which is based on individual income data and expressed in net terms. Then we introduce dummy variables to take into account differences in Gini coefficients due to different methodologies. Thus, if the Gini coefficient is income-based, then dummy $D c=1$, but $D c=0$ otherwise (i.e. income-based). If the Gini coefficient is household-based, then dummy $D h h=1$, but $D h h=0$ otherwise (i.e., individual-based). Finally, if the Gini coefficient is based on gross terms, then dummy $D g=1$, but $D g=0$ otherwise (i.e., based on net terms) [18]. Finally, we introduce country and year fixed effects to capture further possible differences across countries and years, regardless of the source, methodology, and so on, employed.

Therefore, we propose this set of dummies to conveniently capture the heterogeneity contained in the ATG database, as follows [19]:

$$
\text { Dummies }=D_{i}+D_{t}+D_{j}+D_{k}+D c_{i t}+D h h_{i t}+D g_{i t}
$$

where

$$
\begin{aligned}
& D_{i} \quad=1 \text { if country }=i \text {; where } i=1^{\text {st }}, 2^{\text {nd }}, 3^{r d}, \ldots, 62^{\text {nd }} \text { country; } 0 \text { otherwise; } \\
& D_{t} \quad=1 \text { if year }=t \text {; where } t=1990,1991,1992, \ldots, 2015 ; 0 \text { otherwise; } \text { and } \\
& D_{j} \quad=1 \text { if source of observation }=j \text {. }
\end{aligned}
$$

In addition to the Gini coefficient, we also use income shares by quintiles as an additional measure to analyze the relationship between the labor share and inequality. They are obtained only from the World Income Inequality Database (WIID) available at the United Nations University (UNUWIDER), which are available from the poorest $20 \%$ of the population (Quintile 1 or Q1) to the richest $20 \%$ of the population (Quintile 5 or Q5), going through all the five quintiles (Q1, Q2, Q3, Q4 and Q5) to analyze which quintiles drive the relationship. Again we want to maximize the size of the sample, subject to the data being accurate and comparable. Thus, we are restricted to income-based figures in net terms only, provided by the updated Revision New 2017 in this database using only high-quality data to ensure the highest accuracy, consistency and comparability possible. In addition, in the few cases that there is more than one observation per country and year, we stick to the same source in subsequent years whenever possible.

Data on the labor share can also be obtained from different sources based on different methodologies. Again choosing the "right" labor share involves trade-offs, concerning the accuracy and comparability of the data and the size of the sample, as it was the case for inequality. Recent research by Guerriero (2019) has compared up to 6 different measures for the labor share, based on different criteria to account for the remuneration of self-employed persons. An important result emerges from her paper: the six different measures for the labor share behave similarly over time[20]. In this paper the labor share has been obtained
Labor share and income inequality 
from the "Total Economy Database," provided by The Conference Board (TCB), which ranges from 1990 to 2015. The labor share measures the proportion of labor income with respect to total income, and it is based on the compensation of employees and mixed-income data from the national accounts. This is a standard and convenient adjustment in the literature, which assumes that self-employed workers have the same wage rate as employees [21]. In addition, in case of data are not available, some adjustments are made based on common wages and hours or in case that is not possible, estimates from the Penn World Tables or the Asian Productivity Organization are employed, subject to some adjustments for consistency again. This database also assumes a 50\% labor share for countries with no data at all, and that labor share is constant when there are missing data. However, it is important to note that all these " $a$ d hoc" observations have been eliminated from our sample [22]. In addition to TCB, we also use the labor share provided by Karabarbounis and Neiman (2014), which ranges for the period 1975-2012, as a robustness check.

Some recent research has also cast some doubts as to whether the labor share has really declined, thus suggesting that the decline is basically a statistical artifact of the mismeasurement of the labor share. Thus, different factors would account for this decline: the treatment of capital depreciation, indirect taxes and housing (Bridgman, 2017; Rognlie, 2015; Cette et al., 2020), selfemployment (Elsby et al., 2013; Gollin, 2002; Cette et al., 2020), intangible capital (Koh et al., 2020), business owners taking capital instead of labor income (Smith et al., 2019) or time periods analyzed (Cette et al., 2020). However, these factors generally account for a modest amount of the decline in the labor share, although their importance may be greater in some cases. We should note that our analysis focuses on 62 developed and developing countries, as we detail below. Furthermore, as Autor et al. (2020) have recently put, "there is a general consensus that the fall (of the labor share) is real and significant."

Note that we use annual data in this paper to maximize the sample size and to estimate parameters more precisely [23], having made several adjustments both for inequality and the labor share.

We use standard control variables in our analysis, such as gross domain product (GDP) per capita, international financial integration and trade openness. GDP per capita, as measured in constant terms at purchasing power parity (PPP) values, and trade openness, as measured by the sum of exports and imports of goods and services as a share of GDP, are provided by the World Bank World Development Indicators. International financial integration, as measured by the sum of external assets and liabilities as a share of GDP, is provided by Lane and Milesi-Ferretti $(2007,2018)$ and its most recent update.

After organizing these variables for the Gini coefficient, the labor share and the control variables, we obtain a panel data set encompassing 62 countries, listed in the Appendix, over the period 1990 to 2015. After allowing for missing data and the inclusion of lagged values of the dependent variable and control variables, this yields a sample of 724 observations. When focusing on income shares by quintiles, the panel data set is composed of 38 countries, listed in Appendix and 461 observations when lagged values of the dependent variables and control variables are included.

\section{Empirical estimates}

\subsection{Main results}

To test the relationship between the labor share, LaborShare and income inequality [24], as measured by the Gini coefficient (in logs [25]), $G_{i}$, we specify the following regression equation: 


$$
G_{i t}=a_{0}+a_{1} G_{i, t-1}+a_{2} \text { LaborShare }_{i t}+a_{3} G D P p c_{i t}+a_{4} I F I_{i t}
$$$$
+a_{5} \text { Trade }_{i t}+a_{6} D c_{i t}+a_{7} D h h_{i t}+a_{8} D g_{i t}+u_{i t} \text {, }
$$

where:

$D c_{i t}=1$, if inequality observation is consumption-based and 0 otherwise,

$D h h_{i t}=1$ if inequality observation is household-based, 0 otherwise,

$D g_{i t}=1$ if inequality observation is based on gross income, 0 otherwise and

$G D P p c_{i t}$ stands for GDP per capita in PPP constant terms, $I F I_{i t}$ is the degree of international financial integration (as measured by the sum of total external assets and liabilities), Trade is the degree of trade openness (as measured by total exports plus imports) and $u_{i t}$ is the error term, for country $i$ in period $t[26]$.

We have included a lagged dependent variable among the regressors, given that income inequality is a persistent phenomenon, which means that it presumably follows some kind of autoregressive process [27]. The coefficient $a_{2}$ captures the linear relationship between the labor share and income inequality in the benchmark case. Then, we add standard control variables, such as the level of $G D P$ per capita, $G D P p c$, international financial integration, IFI, trade openness, TradeOpenness. Coefficients $a_{6}$ to $a_{8}$ capture the additional (differential) effect of the labor share on economic inequality due to different economic inequality measures, namely, those based on consumption data, on households and on gross terms, respectively [28]. We also add time dummies to capture further possible differences across years.

We use fixed effects $(F E)$ estimation, which allows for free correlation among the additive, unobserved heterogeneity and the explanatory variables. However, by including a lagged dependent variable FE estimates are biased and inconsistent, although this effect may not be too large (Baltagi, 2013, p. 156). Furthermore, despite the fixed effect estimation being somewhat restrictive because heterogeneity is assumed to be additive and to have constant coefficients; this allows robust estimates with the presence of country-specific slopes on the country-specific covariates [29]. We also add all other dummies. We test the regression equation (1) for the FE and the first column in Table 2 exhibits FE estimates for the complete period 1990-2015 with control variables [30]. We find that a lower labor share is associated with a higher Gini coefficient and this relationship is significant. Thus, the estimate obtained, as captured by $a_{2}$, suggests that if the labor share decreases by 1 percentage point, the Gini coefficient increases by approximately $0.26 \%$, that is, for a plausible Gini index of 38, the Gini index would increase 0.10 percentage points approximately. This result is in line with other earlier results, such as Daudey and GarcíaPeñalosa (2007) (around -0.10), Jacobson and Occhino (2012) (ranging from -0.15 to -0.33 ), or, more recently by Sauer et al. (2020) (ranging from -0.07 to -0.14 ), for instance. In addition, we find that higher values of GDP per capita and trade openness are associated with a lower Gini coefficient, whereas higher international financial integration is related to a higher Gini coefficient. The coefficients for the control variables have the expected signs and are consistent with earlier results in the literature [31], but they are not generally significant.

In addition, given the potential endogeneity which may arise in the explanatory variables, we use the system generalized method of moments (GMM) [32]. As is well known, when the dependent variable exhibits persistence and the number of time series observations is relatively small, first-difference GMM [33] may suffer from some estimation bias. In that case, system GMM may be more efficient than the first-difference GMM. Accordingly, we reestimate the regression (1). Note that we use lag two of the dependent variable as an instrument, which is the latest one that is valid under the assumptions of the
Labor share and income inequality 


\begin{tabular}{|c|c|c|c|}
\hline $\begin{array}{l}\text { AEA } \\
28,84\end{array}$ & $\begin{array}{l}\text { Dependent variable: } \\
\text { Gini coefficient (in logs) }\end{array}$ & $\begin{array}{l}\text { Fixed effects } \\
\text { (1) }\end{array}$ & $\begin{array}{l}\text { System GMM } \\
\text { (2) }\end{array}$ \\
\hline 180 & $\begin{array}{l}\text { Lag of dependent variable }\left[a_{1}\right] \\
\text { LaborShare }\left[a_{2}\right] \\
\text { GDPpc }\left[a_{3}\right] \\
\text { IFI }\left[a_{4}\right] \\
\text { TradeOpenness }\left[a_{5}\right]\end{array}$ & $\begin{array}{r}0.4547^{\text {***** }}(0.0859) \\
-0.0026^{* * *}(0.0013) \\
-0.0308(0.2247) \\
0.0170(0.0107) \\
-0.0633^{*}(0.0356)\end{array}$ & $\begin{array}{r}0.6401^{\text {***** }}(0.0773) \\
-0.0036^{* *}(0.0018) \\
-0.2978^{* * * *}(0.0991) \\
0.0243^{* * * *}(0.0085) \\
-0.0747^{* * * *}(0.0214)\end{array}$ \\
\hline 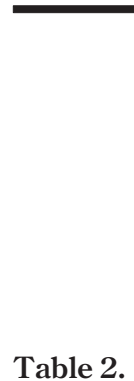 & $\begin{array}{l}\text { Dummy: consumption }\left[a_{6}\right] \\
\text { Dummy: household }\left[a_{7}\right] \\
\text { Dummy: gross income }\left[a_{8}\right] \\
\text { Constant }\left[a_{0}\right] \\
R^{2} \\
\text { No. of observations } \\
\text { No. of countries } \\
\text { No. of instruments } \\
\text { Hansen test } \\
\text { First-order autocorrelation } \\
\text { Second-order autocorrelation }\end{array}$ & $\begin{array}{c}-0.0050(0.0182) \\
0.1310^{* * * * *}(0.0219) \\
-0.0560^{*}(0.0316) \\
-0.3415^{* * * *}(0.1034) \\
0.95 \\
724 \\
62\end{array}$ & $\begin{array}{c}-0.0238(0.0162) \\
0.0434(0.0577) \\
-0.0952^{* *}(0.0423) \\
-0.0777(0.0973) \\
724 \\
62 \\
83 \\
19.57(1.00) \\
-2.53(0.00) \\
-2.33 \\
(0.10)\end{array}$ \\
\hline
\end{tabular}

Labor share and the Gini coefficient, 1990-2015

Notes: Robust standard errors clustered by country are in parenthesis in the upper part of the table. Time and country dummies included. *Significant at $10 \%$ level; ${ }^{* *}$ Significant at $5 \%$ level; ${ }^{* * *}$ Significant at $1 \%$ level. $p$-values for the diagnostic testing of GMM are in parenthesis in the lower part of the table

model. We have also introduced one lag of the dependent variable to capture possible dynamics in the regression below. For dynamic panel data models, the GMM offers more efficient estimates than do the lagged dependent variable fixed-effect model [34]. The system GMM estimation is accompanied by the usual diagnostic testing. The first diagnostic test investigates first- and second-order serial correlations in the disturbances. The absence of a first-order serial correlation should be rejected, but the absence of a second-order serial correlation should not. Second, a Hansen test is performed for the null hypothesis that the overidentifying assumptions are valid, which should not be rejected. Both tests are satisfied. The second column in Table 2 shows the results. They are broadly similar to the results found by FE: there is strong evidence that a higher labor share is associated with a lower Gini coefficient. Now the estimate $a_{2}$ implies that if the labor share decreases by 1 percentage point, the Gini index increases by approximately $0.36 \%$. For instance, if the Gini index was 38, it would increase by $0.14 \%$ points. Again this result is in line with earlier results. The estimates for the control variables confirm previous results by $\mathrm{FE}$. Thus, higher values of GDP per capita and trade openness are associated with a lower Gini coefficient and the opposite is true for higher international financial integration [35]. Again the coefficients for the control variables have the expected signs, but now, on the contrary, the estimates for the control variables are significant.

However, the Gini coefficient is not the only measure to capture economic inequality. The Gini coefficient provides an "average" measure of economic inequality, but it does not indicate the relationship for the poorest or the richest people, for example. To analyze this issue, we use income shares by quintiles from the WIID available at the United Nations University. We focus on the relationship the labor share and the income received in the bottom 20\%, Q1, in the next quintiles, Q2, Q3, Q4 and finally in the top $20 \%$ quintile, $Q 5$. Analogously to equation (1), we test the relationship between the labor share and income 
inequality, as measured by the income share received by the corresponding quintile, $Q j_{i}$, for $j=1,2,3,4,5$, with the following regression equation:

$$
Q j_{i t}=a_{0}+a_{1} Q j_{i, t-1}+a_{2} \text { LaborShare }_{i t}++a_{3} G D P p c_{i t}+a_{4} I F I_{i t}+a_{5} \text { Trade }_{i t}+u_{i t} .
$$

The results are shown in Table 3 for FE. Several patterns emerge. A lower labor share is associated with a lower income share for the lowest quintiles (Q1 to Q3), as captured by the estimated values of the parameter $a_{2}$ and higher for the highest quintiles, for $\mathrm{FE}$, but significant effects are found only for the lowest 2 quintiles and for the highest quintile. In addition, the relationship is stronger for $Q 1$ and it slows down as we move up through higher quintiles up to Q4, then reversing the results for Q5. System GMM estimates confirm these results for all quintiles, as shown in Table 4. These results would suggest that, as pointed out by estimate $a_{2}$, a decrease by 1 percentage point in the labor share is associated with a decrease by $0.0145-0.0324$ (FE-system GMM) percentage points for the income share obtained by the first quintile, 0.0115 to 0.0237 percentage points for the income share by the second quintile, [...] and an increase by 0.0474 to 0.0769 percentage points for the income share by the fifth quintile. These results can be somehow compared with those found recently in Sauer et al. (2020) for inequality at the extremes, even though ours is estimated on income shares by quintiles and theirs is estimated on decile ratios based on relative income shares. Thus, according to the results obtained in Tables 3 and 4, given that a fall by 1 percentage point in the labor share is associated with a decrease by 0.0145 to 0.0324 (FEsystem GMM) percentage points for the income share obtained by the first quintile, and an increase by 0.0474 to 0.0769 percentage points for the income share by the fifth quintile, then this would imply that the quintile ratio between the fifth quintile and the first quintile would increase by $0.0329(=0.0474-0.0145)$ (for FE) or by $0.0445(=0.0769-0.0324)$ (for system GMM) percentage points approximately. On the other hand, Sauer et al. (2020) find that 1 percentage point in the labor share is associated with an increase in the decile ratio between the richest and the poorest decile by 0.007 (0.02) percentage points in high-income OECD (developing) countries (although estimates are not significant). These results would imply that changes in income shares have been stronger for quintile ratios than for decile ratios when the opposite would be expected because quintile ratios are typically lower than decile ratios. The reason behind this discrepancy maybe because of the fact that our sample is focused on the most recent period 1990-2015, where changes in income shares and labor shares have been stronger, whereas Sauer et al. (2020) refers to the period 1981-2010, which has had a lower variability (ILO-OECD-IMF-WB, 2015). In addition, the relationship between the labor share and income shares by quintiles is stronger for the first and second quintiles. This result is related to the findings by Palma (2011), who highlighted that "middle classes," that is, Deciles 5 to 9 , tend to capture around half of the national income, while the other half of national income is shared between the richest $10 \%$ and the poorest $40 \%$, that is, the Decile 10 and the first and second quintiles, i.e. there is "homogeneity" in the middle and upper-middle classes (Deciles 5 to 9) and "heterogeneity" in the tails (Deciles 1 to 4 and Decile 10). Therefore, this fact, which seems robust [36], suggests that changes in the labor share should then be associated mainly with changes in income shares for Deciles 1 to 4, that is, Quintiles 1 to 2 and Decile 10, which is contained in quintile 5 [37]. One of the main reasons behind this result is likely to be related to differences in skills. Thus, as the IMF (2017) has pointed out, "The decline in the global labor share has been borne by lowand middle-skilled labor [38].” And higher (lower) skilled labor receives higher (lower) incomes, thus being part of upper (lower) quintiles [39].
Labor share and income inequality

(1) 
AEA

28,84

\section{2}

Table 3.

Labor share and income shares, by quintiles, 1990-2015. Fixed effects

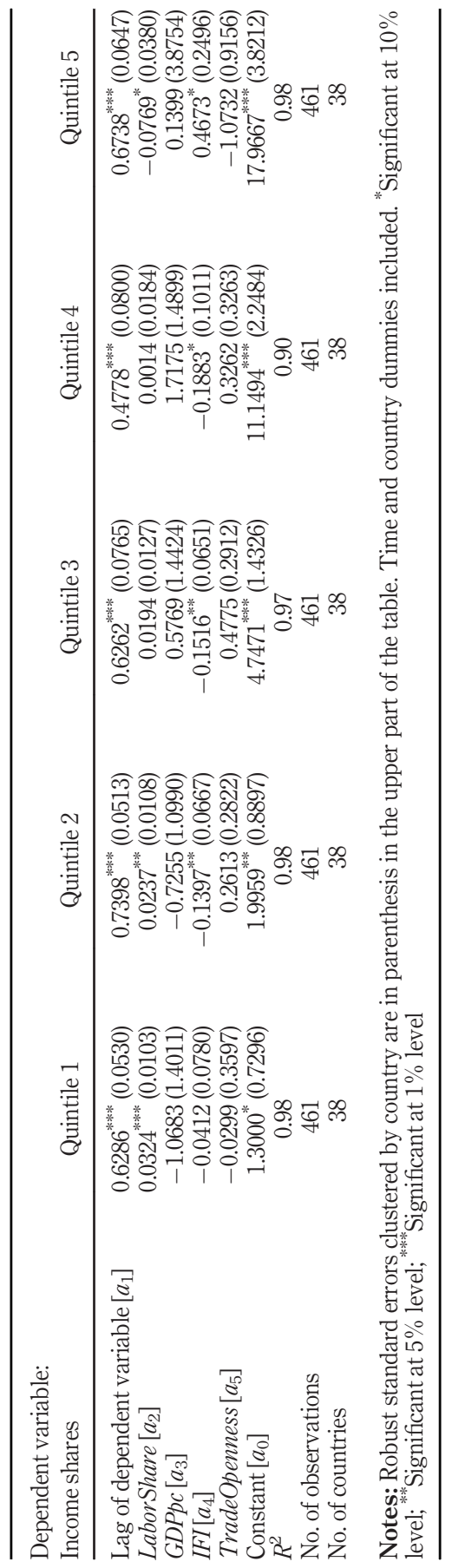




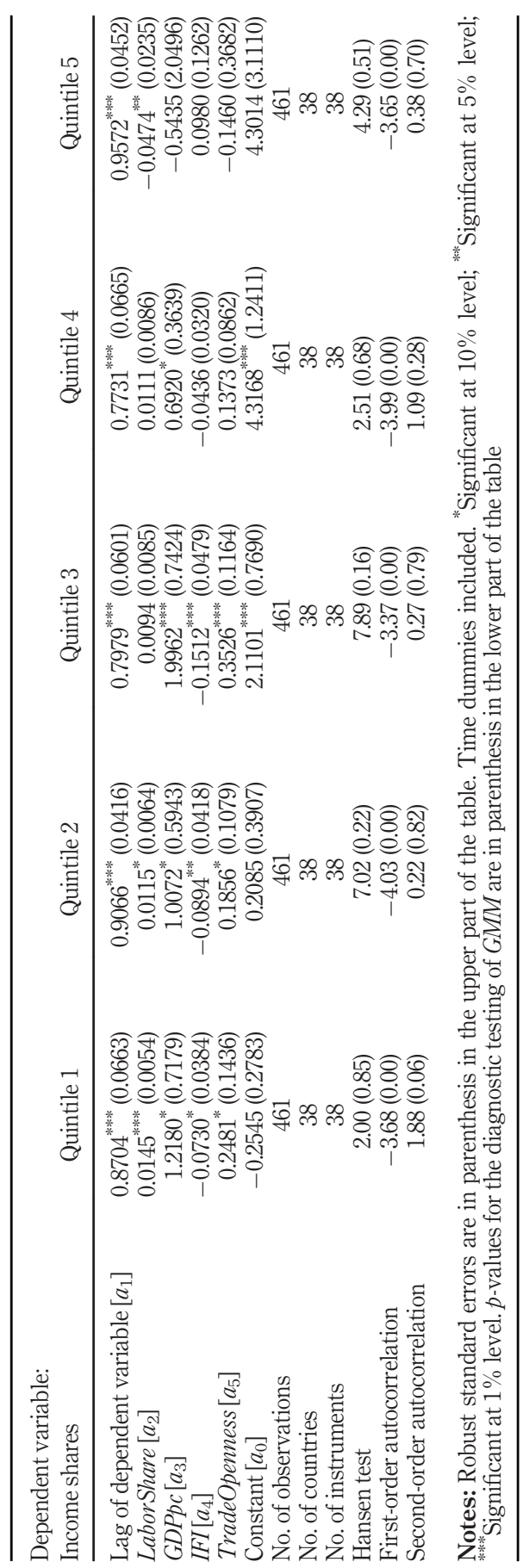

Labor share and income inequality

183

Table 4.

Labor share and income shares, by quintiles, 1990-2015.

System GMM 
AEA 28,84

184

To analyze whether all these results for income shares by quintiles are consistent or not with our earlier result that a lower labor share is associated with a higher Gini coefficient, we adapt the discussion on the "Palma ratio" (as an alternate measure of inequality, such as the ratio of income share by Decile 10 to the income share by Deciles 1 to 4) [40] by Cobham and Sumner (2013), to our setting. We depart from an example based on values for a stylized set of household decile income distributions for the USA for 2010-2015, for expositional simplicity, as shown in Table 5 [41]. We then calculate the associated Gini indices, labor shares and Palma ratios. Thus, for the initial income share by deciles, as shown in Column (1), the Gini index is 46.5, the labor share is $80 \%$ and the Palma ratio is 2.91 . Then, we reduce income shares for Deciles 1 to 4 correspondingly, while income share for Decile 10 increases, so as to keep income shares for Deciles 5 to 9 constant, as in Palma (2011,2016). The results are shown in Column (2). Then the Gini index increases to 49.2, whereas labor share falls 1 percentage-point (to 0.79) and the Palma ratio rises to 3.77. Thus, a lower labor share is associated with a higher Gini coefficient for some plausible values of our stylized income distribution.

Finally, when looking at the control variables for quintiles in Tables 3 and 4 , we find that GDP per capita and trade openness is associated with higher income shares, whereas international financial integration is related to lower-income shares, for the four lowest quintiles. The opposite is found for the highest quintile. Thus, the coefficients of estimates of GDP per capita, international financial integration and trade openness are consistent with our earlier results on the Gini coefficient.

\subsection{Robustness check}

Alternately, we use the database provided by Karabarbounis and Neiman (2014) for the labor share, as a robustness check for our earlier results. The database contains labor shares for various years between 1975 and 2012 for 59 countries. However, most observations correspond to the most recent period and refer to developed countries, as in our sample. The coefficient of correlation between our labor share and that for Karabarbounis and Neiman (2014) is quite high (0.66). When combined with the available data on inequality, then our new sample contains 494 observations for 55 countries.

\begin{tabular}{lcc}
\hline Decile & $\begin{array}{c}\text { Income shares } \\
(1)\end{array}$ & $\begin{array}{c}\text { Income shares } \\
(2)\end{array}$ \\
\hline 1 & 1.00 & 0.80 \\
2 & 2.20 & 1.80 \\
3 & 3.60 & 3.00 \\
4 & 4.60 & 3.80 \\
5 & 6.50 & 6.50 \\
6 & 7.80 & 7.80 \\
7 & 10.40 & 10.40 \\
8 & 12.80 & 12.80 \\
9 & 17.90 & 17.90 \\
10 & 33.20 & 35.40 \\
Gini index & 46.5 & 49.2 \\
Labor share & $80 \%$ & $79 \%$ \\
Palma ratio & 2.91 & 3.77 \\
\hline
\end{tabular}

Table 5.

Income shares per decile, Gini indices, labor shares and Palma ratios
6.50

10.40

12.80

17.90 
We test the regression (1) again and we find similar results, that is, a lower labor share is associated with higher income inequality, as shown in Table 6 for FE and system GMM. Now the estimates obtained, as reflected by $a_{2}$, suggest that if the labor share decreases by 1 percentage point, the Gini index increases by approximately $0.58-0.16$ (FE-system GMM) percent, which would increase the Gini index $0.22-0.06$ percentage points approximately if the Gini index were 38 (as we did above). Again these results are in line with earlier ones. In addition, we find that higher values of trade openness are significantly associated with a lower Gini coefficient, as expected, both for FE and system GMM, whereas higher values of GDP per capita (international financial integration) are associated with a lower (higher) Gini coefficient, as expected, for system GMM, but we get unexpected signs for the FE estimates, albeit not significant.

\begin{tabular}{lcr} 
Dependent variable: & & \\
Gini coefficient & Fixed effects & System GMM \\
Period & $(1)$ & $(2)$ \\
\hline Lag of dependent variable $\left[a_{1}\right]$ & $0.3354^{* * *}(0.1042)$ & $0.7392^{* * *}(0.0601)$ \\
LaborShare $\left[a_{2}\right]$ & $-0.0058^{* *}(0.0026)$ & $-0.0016^{* *}(0.0007)$ \\
GDPpc $\left[a_{3}\right]$ & $0.3260(0.2557)$ & $-0.1703^{* * *}(0.0517)$ \\
$I F I\left[a_{4}\right]$ & $-0.0019(0.0168)$ & $0.0367^{* * *}(0.0114)$ \\
TradeOpenness $\left[a_{5}\right]$ & $-0.0937^{* *}(0.0412)$ & $-0.0650^{* * *}(0.0218)$ \\
Dummy: consumption $\left[a_{6}\right]$ & $-0.0201(0.0277)$ & $-0.0114(0.0182)$ \\
Dummy: household $\left[a_{7}\right]$ & $0.0333(0.0402)$ & $0.0045(0.1014)$ \\
Dummy: gross income $\left[a_{8}\right]$ & $-0.0177(0.0416)$ & $-0.0456(0.0478)$ \\
Constant $\left[a_{0}\right]$ & $-0.4137^{* *}(0.1811)$ & $-0.1745^{* *}(0.0825)$ \\
$R^{2}$ & 0.96 & 494 \\
No. of observations & 494 & 55 \\
No. of countries & 55 & 78 \\
No. of instruments & & $12.98(1.00)$ \\
Hansen test & & $-2.85(0.00)$ \\
First-order autocorrelation & & $1.78(0.09)$ \\
Second-order autocorrelation & &
\end{tabular}

Notes: Robust standard errors clustered by country are in parenthesis in the upper part of the table. Time and country dummies included. "Significant at $10 \%$ level; ${ }^{* * *}$ Significant at $5 \%$ level; ${ }^{* * * *}$ Significant at $1 \%$ level. $p$-values for the diagnostic testing of GMM are in parenthesis in the lower part of the table
Labor share and income inequality

185

Table 6.

Robustness check: the labor share and the Gini coefficient, with the labor share as in Karabarbounis and Neiman (2014)

Parameter values for the model

Production

Preferences

Results of the model

Labor share (\%)

60

58

56

54

52

50

$$
\begin{gathered}
\mathrm{A}=0.60, \alpha=0.60 \\
\gamma=-2, \eta=1.75 \text { and } \beta=0.04
\end{gathered}
$$

$\begin{array}{ccc}1 & \psi \% & \text { Gini } \\ 0.727 & 2.334 & 32.88 \\ 0.728 & 2.209 & 33.62 \\ 0.728 & 2.084 & 34.35 \\ 0.729 & 1.959 & 35.07 \\ 0.729 & 1.946 & 35.79 \\ 0.730 & 1.708 & 36.51\end{array}$

Table 7.

Labor share and the

Gini index 
AEA

28,84

186

\section{Conclusions}

In this paper, we have analyzed how the labor share is related to income inequality, as measured by the Gini coefficient and by the income shares for different quintiles, for the period 1990-2015 for 62 developed and developing countries. We have found that a lower labor share is strongly associated with a higher Gini coefficient and shown why this is so: a lower labor share seems to be strongly associated with a smaller income share for the lowest two quintiles and larger income share for the highest quintile (probably due to differences in skills), and weakly associated with a smaller income share for the third and fourth quintiles. Moreover, we find that the lower the quintile, the stronger the relationship between the labor share and the income share of the quintile. This empirical result has been theoretically motivated by the model by García-Peñalosa and Turnovsky (2006), as shown in the Appendix.

These results suggest that, as long as an increase in income inequality is considered as excessive and unsatisfactory, policymakers should take into account the evolution of the labor share, given that it seems to be closely related to the adverse evolution of the income shares by the poorest and richest quintiles. Thus, public policies that improve labor market outcomes, such as those aimed to promote participation in the labor market and strengthen the human capital of low-income groups, seem necessary to prevent the rise in economic inequalities. Moreover, as the digital transformation of society progresses, policies to promote skill deepening may have an important role to reverse excessive inequalities.

\section{Acknowledgments}

Financial support from Programa de Movilidad del Personal Investigador del Departamento de Educación, Política Lingüística y Cultura del Gobierno Vasco and Programa de apoyo a los grupos del sistema universitario vasco del Departamento de Educación, Política Lingüística y Cultura del Gobierno Vasco (Grupo de investigación IT885-16) is gratefully acknowledged. This paper was written in part while Iñaki Erauskin was visiting the University of Washington. I thank Steve Turnovsky, two anonymous referees and the editor-in-chief, Luis Ayala, for comments on an earlier draft. The remaining errors and omissions are entirely the responsibility of the author.

\section{Notes}

1. See Dao et al. (2017) and IMF (2017), for example, for recent surveys on this issue. Some recent research has cast doubt as to whether the labor share has really declined, suggesting that the decline is basically a statistical artifact of the mis-measurement of the labor share, but, as Autor et al. (2020) have recently put, "there is a general consensus that the fall [of the labor share] is real and significant." We discuss this issue in Section 3 below.

2. See Section 3 for the data sources on the labor share.

3. See Milanovic (2016a) or World Inequality Lab (2017), for instance, for recent evidence.

4. See Section 3 for the data sources on inequality.

5. Labor (capital) share falls (increases) when wages increase more slowly than productivity, which, given that capital tends to be concentrated in the upper ends of the income distribution, the decline in the labor share is likely to be associated with an increase in income inequality.

6. There is a growing literature focusing on the inequality on the top (usually $0.1 \%, 1 \%$ or $10 \%$ ) of the income distribution. See Piketty and Saez (2003), Atkinson et al. (2011), Gabaix et al. (2016) and Saez and Zucman (2016), for instance.

7. See Francese and Mulas-Granados (2015) or IMF (2017), for instance, for brief overviews. 
8. See Acemoglu and Autor (2011) for the original contribution. Autor and Dorn (2013) also document the polarization of wage inequality in the USA for the period 1980-2005, which is also confirmed for 16 Western European countries [Goos et al. (2014)]: employment is strongly U-shaped in skill level, with employment declines in the middle of the distribution and relative gains at the tails.

9. Karabarbounis and Neiman (2014).

10. See De Loecker et al. (2020), Diez et al. (2018) and IMF (2019) for instance.

11. See IMF (2017) for references.

12. See Ferreira et al. (2015, p. 522) and Jenkins (2015, p. 669), for instance.

13. Eight different databases form part of ATG database, where the LIS is considered the best source. See Ravallion (2015) for an excellent review of LIS. Solt (2016, p. 1268) considers the LIS is the "gold standard of cross-nationally comparable inequality data." However, the LIS mainly covers only data for developed countries.

14. See Ferreira et al. (2015) and Jenkins (2015) for recent reviews on SWIID, for instance.

15. In addition, one of the main problems is that the SWIID data are largely regressions that are based on a core of countries for which data exist and are applied to years and countries for which such data do not exist. This is particularly problematical in the case of developing countries that constitute a large proportion of our data set. See Jenkins (2015) for a useful critique of the benefits and costs associated with SWIID database.

16. "Thus, the final Giniall variable had the advantage of covering as many cells (country/years) as possible but the disadvantage that the data were not consistent: a country series might have several values from one source, followed by several values form another and then yet by a third. This led to some confusion: researchers tended to use, for simplicity, Giniall despite the caveat that it was not a homogeneous variable (neither within countries nor between). To avoid such confusion, this version of the data set drops the summary variable." as argued in "the description of $A T G$ data set" (Milanovic, 2019, p. 6).

17. Data from UNU-WIDER for the Gini coefficient have not been employed, because it seems that it is not easy to compare with the rest of the sources [Milanovic (2019, p. 3)]. In fact, it would only add a few more observations to the sample.

18. Note that, in terms of the ATG database, the benchmark case implies that $\mathrm{Di}=1, \mathrm{Dhh}=0$ and $\mathrm{Dg}=0$.

19. I am grateful to Branko Milanovic for his help on the proper accounting for the differences in approach, such as I have adopted here. Of course I bear the entire responsibility for this approach.

20. The similarity is stronger for the four first definitions used in her paper. Thus, the correlation coefficients between different measures for the labor shares are high, 0.9 for most of the cases and higher than 0.75 in any case.

21. The labor share in this paper is equivalent to definition 4 in Guerriero (2019).

22. May 2017 version. See https://www.conference-board.org/data/economydatabase/ for more details on this database.

23. See Baltagi et al. (2009), for instance.

24. We refer to income inequality rather than economic inequality because the regression captures the relationship between the labor share and income inequality, adjusted for different measures of inequality (income-consumption, individual-household and net-gross terms, as shown below).

25. It is quite common to use the logarithm of the Gini coefficient, rather than the level of the Gini coefficient, to better capture its non-linearities and boundedness and to behave more like a normally distributed variable (see Jaumotte $e t$ al., 2013, p. 288, for instance).

Labor share and income inequality 
26. We do not report the dummy variables for alternate sources, country or time, referred to in Section 3.

27. It is convenient for the fixed effects estimation (see below) to allow for the dynamics in the behavior of the dependent variable, which may capture partial adjustment toward the steady state, even though it is biased in dynamic panels. That is why we also introduce a lagged dependent variable on the right hand side when we use a dynamic GMM for the estimation, as we detail below. This method allows us to disregard any country specific time-invariant variable (see Baltagi, Demetriades and Law (2009), for instance).

28. Consumption inequality tends to understate income inequality.

29. See Wooldridge (2005).

30. Robust standard errors are clustered by country in the fixed effects estimation.

31. See Erauskin and Turnovsky (2019), for instance.

32. Arellano and Bover (1995) and Blundell and Bond (1998).

33. Arellano and Bond (1991).

34. The number of instruments is also shown: the number of instruments is relatively small with respect to the number of observations. Too many instruments can weaken the Hansen test of the instruments' joint validity (see Roodman (2009a) for instance). We have used xtabond2 command in the estimation, as developed by Roodman (2009b).

35. We should note that we also introduced technological progress as a control variable in the regression, but it was insignificant for the Gini coefficient and across the quintiles and, as it did not offer any additional insights it is not reported. Technological progress captures the contribution of capital services provided by ICT assets to GDP growth as a share of the contribution of total capital services to GDP growth (which is provided by the "Total Economy Database" produced by TCB), rather than the more usual variable, total factor productivity. Jaumotte et al. (2013) use the percentage of ICT capital over total capital, but we are inclined to use the contribution of capital services for capturing better the impact of the contribution of ICT capital to economic activity.

36. Cobham and Sumner $(2013,2014)$.

37. As noted by Palma (2016), while Decile 9 has the most homogeneous share of all deciles, Decile 10 has a hugely heterogeneous one. Thus, changes in Q5 are very likely to mostly reflect changes in Decile 10.

38. Low-skilled labor refers to workers with primary or lower secondary education, middle-skilled labor to workers with upper secondary, post-secondary or non-tertiary education and high-skilled labor to workers with first-stage tertiary education or higher.

39. According to Eurostat (2020), among the population 18-64 years of age, high-skilled persons recorded higher levels of median equivalized disposable income in 2018 (€22,927 in PPS) than low- (€13,392 in PPS) or middle-skilled (around $€ 18,000$ in PPS) persons. This was the case in all EU countries and other non-EU European countries.

40. The Palma ratio is currently being used by the World Bank and the United Nations, for instance.

41. Note that Atkinson and Lakner (2020) find that, when analyzing factor income decomposition for the top 5\% incomes in the USA for 1961-2006, approximately $35 \%$ of total income accrues to the top $5 \%$, while it is $85 \%$ for capital income and $28 \%$ for labor income. Around $80 \%$ of total income corresponds to labor share, while capital share is "only" $20 \%$. Thus, even though capital share is typically around $\frac{2}{3}$, Atkinson and Lakner (2020) find that $80 \%$ is a more accurate measure, as does Piketty and Saez (2007). Why? According to Atkinson and Lakner (2020), the capital share is underestimated because capital gains which do not reflect undistributed capital 
gains are excluded in national accounts, and, additionally, total dividends in national accounts exceed those reported on tax returns, because the former also include non-taxable dividends paid out through funded pension plans or retirement savings accounts. Furthermore, Milanovic (2017) points out that, when using data to calculate inequality (such as those provided by the LIS), capital income is probably underestimated in many cases, because the rich (who receive a high share of income from capital) refuse to participate in surveys or underestimate their capital income. Interestingly, Milanovic calculates that the Gini coefficient of capital income in the USA is around 0.90, not far from the figure we would get in our stylized example.

42. García-Peñalosa and Turnovsky (2008) also analyze the transitional dynamics of income and wealth inequality in a Ramsey model, but we will not refer to it for expositional simplicity.

43. These properties are necessary for marginal product factor pricing to be consistent with a competitive equilibrium.

44. Inada conditions are satisfied as well.

45. In general, the coefficient of relative risk aversion equals $1-\gamma$ and the logarithmic utility function is equivalent to $\gamma=1$.

46. The empirical evidence suggests a high degree of relative risk aversion, such as $\gamma<0$.

47. The restrictions on the elasticities $\gamma$ and $\eta$ in (7) are to ensure that the utility function is concave in $C_{i}$ and $l_{i}$. The intertemporal elasticity of substitution is equal to $\frac{1}{1-\gamma}$. When $\gamma=0$ this function corresponds to the logarithmic utility function.

48 See Wolff (2010).

\section{References}

Acemoglu, D. and Autor, D.H. (2011), "Skill, tasks and technologies: implications for employment and earnings", In Handbook of Labor Economics, Volume 4. Elsevier, Amsterdam.

Adler, M. and Schmid, K.D. (2013), "Factor shares and income inequality. Empirical evidence from Germany 2002-2008”, Schmollers Jahrbuch, Vol. 133 No. 2, pp. 121-132, doi: 10.3790/ schm.133.2.121.

Alvaredo, F. (2011), "A note on the relationship between top income shares and the Gini coefficient", Economics Letters, Vol. 110 No. 3, pp. 274-277.

Arellano, M. and Bond, S. (1991), "Some tests of specification for panel data: Monte Carlo evidence and an application to employment equations", The Review of Economic Studies, Vol. 58 No. 2, pp. 277-297.

Arellano, M. and Bover, O. (1995), "Another look at the instrumental variable estimation of errorcomponents models", Journal of Econometrics, Vol. 68 No. 1, pp. 29-51.

Atkinson, A.B. and Lakner, C. (2020), "Capital and labor: the factor income composition of top incomes in the United States, 1962-2006", Review of Economics and Statistics, (accepted for publication).

Atkinson, A.B., Piketty, T. and Saez, E. (2011), "Top incomes in the long run of history", Journal of Economic Literature, Vol. 49 No. 1, pp. 3-71.

Autor, D.H. and Dorn, D. (2013), "The growth of Low-Skill service jobs and the polarization of the US labor market", American Economic Review, Vol. 103 No. 5, pp. 1553-1597.

Autor, D., Dorn, D., Katz, L., Patterson, C. and van Reenen, J. (2020), "The fall of the labor share and the rise of superstar firms", Quarterly Journal of Economics, Vol. 135 No. 2, pp. 645-709.

Baltagi, B.H. (2013), Econometric Analysis of Panel Data, 5th ed., John Wiley and Sons.

Baltagi, B.H., Demetriades, P. and Law, S.H. (2009), "Financial development and openness: evidence from panel data", Journal of Development Economics, Vol. 89 No. 2, pp. 285-296.

Blundell, R. and Bond, S. (1998), "Initial conditions and moment restrictions in dynamic panel data models", Journal of Econometrics, Vol. 87 No. 1, pp. 115-143. 
AEA 28,84

Bridgman, B. (2017), "Is labor's loss capital's gain? Gross versus net labor shares", Macroeconomic Dynamics, Vol. 22 No. 8, pp. 1-18.

Cette, G., Koehl, L. and Philippon, T. (2020), “Labor share”, Economics Letters, Vol. 118 (March).

Checchi, D. and García-Peñalosa, C. (2010), "Labour market institutions and the personal distribution of income in the OECD”, Economica, Vol. 77, pp. 413-450.

Cobham, A. and Sumner, A. (2013), "Is it all about the tails? The Palma measure of income inequality", CGD working paper 343, Center for Global Development, Washington, DC. www.cgdev.org/ publication/it-all-about-tails-palma-measure-income-inequality

Cobham, A. and Sumner, A. (2014), "Is it all about the tails?", Significance, Vol. 11 No. 1, pp. 10-13.

Dao, M.-C., Das, M., Koczan, Z. and Lian, W. (2017), "Why is labor receiving a smaller share of global income? Theory and empirical evidence", IMF Working Paper WP/17/169.

Daudey, E. and García-Peñalosa, C. (2007), "The personal and the factor distributions of income in a cross-section of countries", The Journal of Development Studies, Vol. 43 No. 5, pp. 812-819.

De Loecker, J., Eeckhout, J. and Unger, G. (2020), "The rise of market power and the macroeconomic implications”, The Quarterly Journal of Economics, Vol. 135 No. 2 (May), pp. 561-644.

Diez, M.F. Leigh, M.D. and Tambunlertchai, S. (2018), "Global market power and its macroeconomic implications”, IMF working paper No. 18/137, available at www.imf.org/en/Publications/WP/ Issues/2018/06/15/Global-Market-Power-and-its-Macroeconomic-Implications-45975

Elsby, M.W.L., Hobijn, B. and Şahin, A. (2013), “The decline of the U.S. Labor share”, Brookings Papers on Economic Activity, Vol. 2013 No. 2, pp. 1-52.

Erauskin, I. and Turnovsky, S.J. (2019), "International financial integration and income inequality in a stochastically growing economy", Journal of International Economics, Vol. 119, pp. $55-74$.

Eurostat (2020), "Living conditions in Europe - income distribution and income inequality", available at: https:/ec.europa.eu/eurostat/statistics-explained/index.php/Living_conditions_in_Europe_-income_distribution_and_income_inequality\#Income_distribution

Ferreira, F.H.G., Lustig, N. and Teles, D. (2015), "Appraising cross-national income inequality databases: an introduction”, The Journal of Economic Inequality, Vol. 13 No. 4, pp. 497-526.

Francese, M. and Mulas-Granados, C. (2015), "Functional income distribution and its role in explaining inequality”, IMF Working Papers WP/15/244.

Gabaix, X., Lasry, J.-M., Lions, P.-L. and Moll, B. (2016), "The dynamics of inequality”, Econometrica, Vol. 84 No. 6, pp. 2071-2111.

García-Peñalosa, C. and Turnovsky, S.J. (2006), "Growth and income inequality: a canonical model”, Economic Theory, Vol. 28 No. 1, pp. 25-49.

García-Peñalosa, C. and Turnovsky, S.J. (2008), "Distributional dynamics in a neoclassical growth model: the role of elastic labor supply”, Journal of Economic Dynamics and Control, Vol. 32, pp. 1399-1431.

Gollin, D. (2002), "Getting income shares right”, Journal of Political Economy, Vol. 110 No. 2, pp. 458-474.

Goos, M., Manning, A. and Salomons, A. (2014), "Explaining job polarization: Routine-Biased technological change and offshoring”, American Economic Review, Vol. 104 No. 8, pp. 2509-2526.

Guerriero, M. (2019), The Labor Share of Income around the World: evidence from a Panel Dataset. ADBI Working Paper 920, Asian Development Bank Institute, Tokyo. available at: www.adb. org/publications/labor-share-income-around-world-evidence-panel-dataset

ILO-OECD-IMF-WB-International Labour Organization-Organisation for Economic Co-operation and Development, with contributions from International Monetary Fund and World Bank Group (2015), "The labour share in G20 economies", available at: www.oecd.org/g20/topics/ employment-and-social-policy/The-Labour-Share-in-G20-Economies.pdf

IMF-International Monetary Fund (2017), “Gaining momentum?”, World Economic Outlook, April. 
IMF-International Monetary Fund (2019), "The rise of corporate market power and its macroeconomic effects", World Economic Outlook, April.

Jacobson, M. and Occhino, F. (2012), "Labor's declining share of income and rising inequality”, Federal Reserve Bank of Cleveland, available at: www.clevelandfed.org/newsroom-and-events/ publications/economic-commentary/economic-commentary-archives/2012-economic-commentaries/ ec-201213-labors-declining-share-of-income-and-rising-inequality.aspx

Jaumotte, F., Lall, S. and Papageorgiou, C. (2013), "Rising income inequality: technology, or trade and financial globalization?”, IMF Economic Review, Vol. 61 No. 2, pp. 271-309.

Jenkins, S.P. (2015), "World income inequality databases: an assessment of WIID and SWIID”, The Journal of Economic Inequality, Vol. 13 No. 4, pp. 629-671.

Karabarbounis, L. and Neiman, B. (2014), "The global decline of the labor share”, The Quarterly Journal of Economics, Vol. 129 No. 1, pp. 61-103.

Koh, D., Santaeulalia-Llopis, R. and Zheng, Y. (2020), "Labor share decline and intellectual property products capital", Econometrica (accepted for publication).

Lane, P.R. and Milesi-Ferretti, G.M. (2007), "The external wealth of nations mark II: Revised and extended estimates of foreign assets and liabilities, 1970-2004", Journal of International Economics, Vol. 73 No. 2, pp. 223-250.

Lane, P.R. and Milesi-Ferretti, G.M. (2018), "International financial integration in the aftermath of the global financial crisis", IMF Economic Review, Vol. 66 No. 1, pp. 189-222.

Milanovic, B. (2016a), "Global inequality", A New Approach for the Age of Globalization, The Belknap press of Harvard University Press.

Milanovic, B. (2016b), All the Ginis database (version October 2016), available at: www.gc.cuny.edu/ Page-Elements/Academics-Research-Centers-Initiatives/Centers-and-Institutes/Stone-Center-onSocio-Economic-Inequality/Core-Faculty,-Team,-and-Affiliated-LIS-Scholars/Branko-Milanovic/ Datasets

Milanovic, B. (2017), "Increasing Capital income share and its effect on personal income inequality", in Heather Boushey, J. Bradford DeLong and Marshall Steinbaum (Eds.). After Piketty: The Agenda for Economics and Inequality, Harvard University Press, Chapter 10, pp. 235-258.

Milanovic, B. (2019), All the Ginis database (version February 2019), available at: www.gc.cuny.edu/ Page-Elements/Academics-Research-Centers-Initiatives/Centers-and-Institutes/Stone-Center-onSocio-Economic-Inequality/Core-Faculty,-Team,-and-Affiliated-LIS-Scholars/Branko-Milanovic/ Datasets

Palma, J.G. (2011), “Homogeneous middles vs. heterogeneous tails, and the end of the 'Inverted-U': the share of the rich is what it's all about", Development and Change, Vol. 42 No. 1, pp. 87-153.

Palma, J.G. (2016), "Do nations just get the inequality they deserve? The 'Palma ratio' re-examined", Cambridge Working Paper Economics: 1627.

Piketty, T. and Saez, E. (2003), "Income inequality in the United States, 1913-1998", The Quarterly Journal of Economics, Vol. 118 No. 1, pp. 1-39.

Piketty, T. and Saez, E. (2007), "Income andWage inequality in the United States", In: A.B. Atkinson and T. Piketty (eds.): Top Incomes over the Twentieth Century: A Contrast between Continental European and English-Speaking Countries, Oxford University Press.

Ravallion, M. (2015), “The Luxembourg income study”, The Journal of Economic Inequality, Vol. 13 No. 4, pp. 527-547.

Rognlie, M. (2015), "Deciphering the fall and rise in the net capital share: accumulation or scarcity?", Brookings Papers on Economic Activity, Vol. 2015 No. 1, pp. 1-69.

Romer, P.M. (1986), "Increasing returns and long-run growth”, Journal of Political Economy, Vol. 94 No. 5, pp. 1002-1037.

Labor share and income inequality 
Roodman, D. (2009a), "A note on the theme of too many instruments", Oxford Bulletin of Economics and Statistics, Vol. 71 No. 1, pp. 135-158.

Roodman, D. (2009b), "How to do xtabond2: an introduction to difference and system GMM in stata", The Stata Journal: Promoting Communications on Statistics and Stata, Vol. 9 No. 1, pp. 86-136.

Saez, E. and Zucman, G. (2016), "Wealth inequality in the United States since 1913: evidence from capitalized income tax data", The Quarterly Journal of Economics, Vol. 131 No. 2, pp. 519-578.

Sauer, P., Rao, N.D. and Pachauri, S. (2020), "Explaining income inequality trends", An integrated approach WIDER Working Paper 2020/65.

Smith, M., Yagan, D., Zidar, O. and Zwick, E. (2019), "Capitalists in the Twenty-First Century", Quarterly Journal of Economics, Vol. 134 No. 4, pp. 1675-1745.

Solt, F. (2009), "Standardizing the world income inequality database”, Social Science Quarterly, Vol. 90 No. 2, pp. 231-242.

Solt, F. (2016), “The standardized world income inequality database”, Social Science Quarterly, Vol. 97 No. 5, SWIID Version 6.1, October 201.

Wolff, E. (2010), "Recent trends in household wealth in the United States: rising debt and the Middle class squeeze: an update to 2007", https://papers.ssrn.com/sol3/papers.cfm?abstract_id=1585409

Wooldridge, J.M. (2005), "Fixed-effects and related estimators for correlated random-coefficient and treatment-effect panel data models", Review of Economics and Statistics, Vol. 87 No. 2, pp. 385-390.

World Inequality Lab (2017), World Inequality Report 2018. Coordinated by F. Alvaredo, L. Chancel, T. Piketty, E. Saez, and G. Zucman, World Inequality Lab.

\section{Appendix}

A. A simple model for the relationship between the labor share and income inequality This relationship between the labor share and income inequality can be conveniently modeled using a simple example, derived from a stylized model built by García-Peñalosa and Turnovsky (2006) to analyze the relationship between economic growth and income inequality. We provide only the basic details of a numerical example based on their model to exhibit the main result for the relationship between the labor share and income inequality. The reader is referred to as García-Peñalosa and Turnovsky (2006) for more details [42].

\section{A.1 Technology and factor payments}

The economy consists of a fixed number of firms indexed by $\mathrm{j}$. The representative firm produces output in accordance with the production function:

$$
Y_{j}=F\left(L_{j} K, K_{j}\right)
$$

where $K_{j}$ denotes the individual firm's capital stock, $L_{j}$ denotes the individual firm's labor, $K$ is the average stock of capital in the economy, and thus $L_{j} K$ measures the efficiency units of labor employed by the firm. Production has positive but diminishing marginal physical products and constant returns to scale in private capital, $K_{j}$, and in labor measured in efficiency units, $L_{j} K$. Therefore, the production function has constant returns to scale both in the accumulating factors, $K_{j}$ and $K$, necessary for endogenous growth and in the private factors $K_{j}$ and $L_{j}[43]$.

All firms face identical production conditions. Hence, they will all choose the same level of employment and capital stock. That is, $K_{j}=K$ and $L_{j}=L$ for all $j$, where $L$ is the average economywide level of employment. The average capital stock yields an externality such that in equilibrium the aggregate (average) production function is linear in the aggregate capital stock[44], as in Romer (1986), namely: 


$$
Y=F(L K, K) \equiv f(L) K
$$

where $f^{\prime}(L)>0$ and $f^{\prime \prime}(L)<0$.

The wage rate and the return to capital are determined by their respective marginal physical products. Differentiating the production function and given that firms are identical, we obtain:

$$
\begin{gathered}
\left(\frac{\partial F}{\partial L_{j}}\right)_{K_{j}=K ; L_{j}=L}=f^{\prime}(L) K \equiv \omega(L) K, \\
\left(\frac{\partial F}{\partial K_{j}}\right)_{K_{j}=K ; L_{j}=L}=f(L)-L f^{\prime}(L) \equiv r(L) .
\end{gathered}
$$

Thus, the equilibrium return to capital is independent of the stock of capital while the wage rate is proportional to the average stock of capital, and therefore grows with the economy. In addition, we have $r^{\prime}(L)=-L f^{\prime}(L)>0$ and $\omega^{\prime}(L)=-f^{\prime}(L) K<0$, i.e. more employment raises the productivity of capital but lowers the productivity of labor.

\section{A.2 Consumers}

The economy is populated by a mass 1 of infinitely-lived consumers, indexed by $i$. They are identical in all respects except for their initial endowment of capital, $K_{i, 0}$. As the economy is growing we focus on the relative shares of individual $i$ 's holding of capital, $k_{i}(t) \equiv K_{i}(t) / K(t)$, where $K(t)$, denotes the corresponding economy-wide average quantity. Relative capital has a distribution function $D\left(k_{i}\right)$, mean $\sum k_{i}=1$ and variance $\sigma_{k}^{2}$.

Each agent has one unit of time that can be allocated to labor $L_{i}$ or to leisure, $l_{i}$. Thus, the agent's objective is to select his portfolio of assets, the rate of consumption and leisure to maximize expected lifetime utility, represented by the isoelastic utility function[45]

$$
\begin{gathered}
\int_{0}^{\infty} \frac{1}{\gamma}\left(C_{i} l_{i}^{\eta}\right)^{\gamma} e^{-\beta t} d t, \\
-\infty<\gamma<1 ; \eta>0 ; \gamma(1+\eta)<1,
\end{gathered}
$$

where the Arrow-Pratt coefficient of relative risk aversion is given by the expression $1-\gamma[46]$. The parameter $\eta$ represents the elasticity of leisure in utility[47].

The capital accumulation equation is then given by:

$$
\dot{K}_{i}=r K_{i}+\left(1-l_{i}\right) w K-C_{i} .
$$

With the equilibrium wage rate being tied to the aggregate capital stock, as shown in (8), the individual's rate of capital accumulation depends on the aggregate stock of capital, which the individual takes as given. There is no government for simplicity.

\section{A.3 Macroeconomic equilibrium}

The equilibrium solution to the macroeconomic model is captured by two equations, $R R$ and $P P$ : 


$$
\begin{gathered}
R R: \psi=\frac{f(1-l)-(1-l) f^{\prime}(1-1)-\beta}{1-\gamma} \\
P P: \psi=f(1-l)-\frac{l f^{\prime}(1-1)}{\eta},
\end{gathered}
$$

where $\psi$ refers to the balanced growth rate of capital, $l$ to the fraction of time allocated to leisure, $L=$ 1-1 to the fraction of time for labor, $\beta$ to the rate of time discount, $\eta$ to the elasticity of leisure in utility and $\gamma$ to the degree of relative risk aversion, which corresponds to the intertemporal elasticity of substitution $\frac{1}{1-\gamma}$. The production function $f(L)=f(1-l)$ exhibits the usual properties. The $R R$ equation describes the relationship between the balanced growth rate of capital, $\psi$ and the fraction of time allocated to leisure, $l$, where the risk-adjusted rate of return to capital and return to consumption are equalized. The $P P$ equation describes the relationship between the growth rate and leisure to maintain product market equilibrium. Both curves are decreasing in leisure. Thus, for the $R R$ curve, more leisure time reduces the productivity of capital and this, in turn, requires a fall in the return to consumption. This is obtained if the growth of the marginal utility of consumption rises, that is, if the growth rate of capital falls. For the curve $P P$, more time dedicated to leisure reduces output, thus increasing the consumption-output ratio and this, in turn, reduces the growth rate of capital.

We use a Cobb-Douglas production function, $Y=A L^{\alpha} K$ and use standard parameter values, as shown in Table 7 (upper table). The initial choice of production elasticity of labor measured in efficiency units, $\alpha=0.60$, implies that $60 \%$ of output is received by labor. The rate of time preference of $4 \%$ is standard. The choice of the elasticity on leisure, $\eta=1.75$, is common for the real business cycle literature; this implies that about $72 \%$ of the time is devoted to leisure, consistent with empirical evidence. The degree of relative risk aversion is equal to -2 , in line with the empirical evidence; this implies that the intertemporal elasticity of substitution is equal to $\frac{1}{3}$, which falls between the usual values of 0 and 1 . The productivity parameter, $A=0.60$, is convenient for plausible values of the equilibrium capital-output ratio.

Obtaining the standard measure of inequality, i.e. the Gini index, involves choosing an initial distribution of wealth, which is less straightforward, as data on the distribution of wealth are difficult to obtain. We have assumed that the distribution of wealth among the 5 quintiles is $0,0,1.2 \%, 12 \%$, $86.8 \%$, which is consistent with the data (García-Peñalosa and Turnovsky, 2006). For example, in the US in 1992 the bottom $40 \%$ of the population held $0.4 \%$ of total wealth, while the top $20 \%$ owned $83.8 \%$ of the total[48]. It is also assumed that the bottom quintile has no labor income because their model has no heterogeneity in wages, which would tend to compress the distribution of income.

The first line of Table 7 (lower table) reports the benchmark equilibrium for our base parameters with a labor share of $60 \%$. It indicates that $72.7 \%$ of the time is allocated to leisure, yielding a growth rate of $2.3 \%$ and the Gini index is 32.88 , which is a plausible benchmark. The next five lines in Table 7 report the effect of the reduction in the weight of labor share from $60 \%$ to $50 \%$. For instance, the choice of a labor share of $56 \%$, which was approximately the case in 1990, yields a Gini index of almost 34.4, which compares with the average 36.7 for 1990 for our sample. The choice of a labor share of $50 \%$, which was approximately the case in 2015 , yields a Gini index of 36.5, which compares with the average 40.1 for 2015 for our sample. Thus, while the change in the Gini index of our model is about $6.1 \%$, the actual change has been about $9.3 \%$. Overall, these simulations show that the predictions of the model can explain a good deal of the change in inequality and are in line with the finding that a lower labor share is associated with higher income inequality. 
Intuitively, a fall in the weight of labor in the production function, $\alpha$, as in the Cobb-Douglas production function, $Y=A L^{\alpha} K$, shifts the production function. Thus, a fall in the labor share leads to an upward shift in both the $R R$ and $P P$ curves. On the one hand, a decline in the labor share increases the productivity of capital, which, in turn, implies an upward shift in the $R R$ curve, analogous to the case of an increase in productivity. At the same time, a fall in the labor share leads also to an upward shift of the $P P$ curve, to guarantee market clearing. However, the upward shift in the $P P$ curve has offsetting effects, causing an increase in leisure accompanied by a lower growth rate of capital. On impact, given labor supply and output, this lowers the growth rate and the return on consumption, causing agents to reduce consumption and increase leisure. This causes a reduction in output and the growth rate, leading to a reduction in the return to capital and consumption. On balance the latter effect dominates and the new equilibrium is associated with a lower growth rate and more leisure. As labor is more equally distributed than capital, the income gap between any two individuals rises and income inequality increases.

\section{B. List of countries "All the Ginis" database}

- High income developed OECD countries: Australia, Austria, Belgium, Canada, Cyprus, Czech Republic, Denmark, Finland, France, Germany, Greece, Ireland, Italy, Republic of Korea, the Netherlands, Norway, Portugal, Spain, Sweden, Switzerland, UK and USA.

- Other high-income countries: Croatia, Estonia, Israel, Lithuania, Malta, Poland, Romania, Slovak Republic and Slovenia.

- Middle-income countries: Belarus, Brazil, China, Colombia, Costa Rica, Ecuador, Iran, Kazakhstan, Macedonia FYR, Malaysia, Mexico, Peru, Russian Federation, South Africa, Thailand, Turkey, Uruguay and Venezuela.

- Middle-Low income countries: Bangladesh, Egypt, Guatemala, India, Indonesia, Morocco, Nigeria, Pakistan, Sri Lanka, Tajikistan and Ukraine.

- Low-income countries: Senegal and Tanzania.

\section{List of countries WIID}

- High income developed OECD countries: Austria, Belgium, Cyprus, Czech Republic, Denmark, Finland, France, Germany, Greece, Ireland, Italy, Malta, the Netherlands, New Zealand, Norway, Portugal, Spain, Sweden, Switzerland and UK.

- Other high-income countries: Croatia, Estonia, Lithuania, Poland, Romania, Slovak Republic and Slovenia.

- Middle-income countries: Brazil, Colombia, Costa Rica, Ecuador, Macedonia FYR, Mexico, Peru, Turkey, Uruguay and Venezuela.

- Middle-Low income countries: Guatemala.

Corresponding author

Iñaki Erauskin can be contacted at: inaki.erauskin@deusto.es

For instructions on how to order reprints of this article, please visit our website:

www.emeraldgrouppublishing.com/licensing/reprints.htm

Or contact us for further details: permissions@emeraldinsight.com 